\title{
A utilização de atividades diversificadas no processo de ensino-aprendizagem da Primeira Lei de Mendel
}

Vitor Garcia Stoll

Crisna Daniela Krause Bierhalz

\section{Resumo}

O presente relato apresenta um recorte das atividades sobre a Primeira Lei de Mendel, desenvolvidas em uma turma da Educação de Jovens e Adultos (EJA), durante o Estágio Supervisionado do Curso de Licenciatura em Ciências da Natureza, vinculado a Universidade Federal do Pampa - Campus Dom Pedrito. São objetivos desta proposta: avaliar o domínio conceitual da Primeira Lei de Mendel a partir de diferentes atividades; diferenciar os conceitos de genótipo e fenótipo, homozigoto e heterozigoto; e prever a provável ocorrência de características a partir da aplicação de cruzamentos. Entre as atividades, a de múltipla escolha foi especificada como a de maior complexidade, não pelo conteúdo e sim pelo formato, marcar uma alternativa correta, evidenciando a necessidade fomentar esse formato de atividade na EJA. Além disso, percebeu-se a relevância do feedback, pois possibilitou a recuperação paralela, permitindo ao estudante refletir, repensar e reformular determinado resultado, caso necessário.

Palavras-chave: Lei de Mendel. Feedback. Ensino de Genética. 


\section{The use of diversified activities in the teaching-learning process of Mendel's First Law}

Vitor Garcia Stoll

Crisna Daniela Krause Bierhalz

\section{Abstract}

This report presents a section of the activities on Mendel's First Law, developed in a group of Youth and Adult Education (EJA), during the Supervised Internship of the Degree Course in Natural Sciences, linked to the Federal University of Pampa - Campus Dom Pedrito. The objectives of this proposal are: to evaluate the conceptual domain of Mendel's First Law from different activities; differentiate the concepts of genotype and phenotype, homozygous and heterozygous; and predict the probable occurrence of characteristics from the application of crosses. Among the activities, the multiple choice was specified as the most complex, not for the content but for the format, to mark a correct alternative, highlighting the need to encourage this activity format in the EJA. In addition, the relevance of feedback was perceived, as it enabled parallel recovery, allowing the student to reflect, rethink and reformulate a certain result, if necessary.

Keywords: Mendel's law. Feedback. Genetics teaching. 


\section{Proposições iniciais sobre a $1^{\text {a }}$ Lei de Mendel}

No Ensino de Biologia, muitas vezes, o conteúdo de genética é caracterizado como complexo pelos estudantes, pois necessita do aporte de diferentes áreas do conhecimento. De acordo com Borges, Silva e Reis (2017) o Ensino de Genética é transdisciplinar, pois engloba conceitos matemáticos, físicos, interpretativos, lógicos, dentre outros.

Moura e colaboradores (2013) destacam que a contextualização do conteúdo de genética, o material para apresentação do assunto e a metodologia utilizada em sala de aula também influenciam no interesse dos estudantes. Desse modo, torna-se necessário estimular a interação, a criatividade e o protagonismo discente, e atividades diversificadas que podem ser organizadas em um portfólio, caracterizado como potencializador dessas habilidades.

Com base nesses pressupostos teóricos, apresenta-se neste relato um recorte das atividades desenvolvidos durante o Estágio Supervisionado da Licenciatura em Ciências da Natureza, tendo como conteúdo a Primeira Lei de Mendel. Participaram os educandos da totalidade nove da Educação de Jovens e Adultos (EJA), 17 mulheres e sete homens, com idades entre 18 e 70 anos. A média aritmética etária foi de 28 anos.

A atividade foi organizada em três encontros, total de 5 horas, distribuídas em abordagem conceitual, aplicação de instrumentos avaliativos e feedback. No primeiro, contextualizou-se a história de Mendel, com intuito de mostrar a relevância deste pesquisador para o Ensino de Genética. Foram reproduzidos os cruzamentos feitos com as ervilhas e apresentadas características humanas que seguem os princípios desta lei. No segundo encontro, ocorreu a interpretação de uma charge e tirinha sobre o conteúdo e a realização de exercícios de múltipla escolha. E no último, trabalhou-se com o feedback das atividades, proporcionando aos estudantes refazê-las caso necessário.

\section{Desenvolvimento das atividades sobre a Primeira Lei de Mendel}

Conforme corrobora Lopes (2002), na escola, o conhecimento e os conceitos científicos (teorias, leis e estudos) não devem ser descontextualizados e desvinculados de sua historicidade, pois não são estanques, sem origem, tampouco isolados. Uma lei científica, como a abordada neste relato, emerge a partir de observações, de análises minuciosas e da contribuição dos cientistas.

Considerando o exposto, o primeiro encontro, $1 \mathrm{~h} 30 \mathrm{~min}$, foi destinado a abordagem teórico conceitual, no qual contextualizou-se a história de Gregor Johann Mendel (1822 - 1884), biólogo botânico considerado o "pai da genética”, trabalhava em um monastério na cidade de Brünn, na Austrália (hoje Brno, na República Tcheca). Dedicou-se por muito tempo a sucessivos cruzamentos de animais e vegetais. (ASTRAUSKAS et al., 2009). Porém, foi com as ervilhas da espécie Pisumsativum (Linnaeus 1753), que obteve resultados 
significativos, pois apresenta morfologia contrastante, fácil cultivo, grande produção de sementes, autofecundação e fecundação-cruzada. (LINHARES; GEWANDSZNAJDER, 2010).

Para explicar as características dominantes e recessivas dessas ervilhas, projetou-se uma imagem com suas particularidades: altas (mais de $2 \mathrm{~m}$.) ou baixas (menos de o,5 m.); semente de cor amarela ou verde; forma lisa ou rugosa; flor púrpura ou branca; posicionadas ao longo do caule ou nas pontas; cor da vagem verde ou amarela; com formato liso ou ondulado, respectivamente. (GRIFFITHS et al., 1998).

Retomou-se conceitos fundamentais de genética, associados a imagem: alelos, gene dominante, gene recessivo, homozigose, heterozigose, genótipo e fenótipo. Considera-se importante o domínio conceitual dos termos, pois auxiliam na compreensão da Primeira Lei de Mendel.

Na sequência, com o intuito de demonstrar o procedimento realizado pelo monge escolheu-se uma característica da figura projetada, a cor da vagem: verde (dominante) e amarela (recessivo). Construiu-se um esquema semelhante ao da Imagem 1, explicando cada etapa. Demarcou-se que o êxito nos seus cruzamentos se deve a dois fatores: análise de uma característica por vez, sem se preocupar com as demais; e grande número de descendentes em cada geração, descartando conclusões por coincidência. Para os seus experimentos, Mendel teve o cuidado de utilizar plantas de linhagens puras, que só originassem descendentes com a mesma característica. (SNUSTAD; SIMMONS, 2001).

Imagem 1: Cruzamento realizado por Mendel com ervilhas (representação para cor da vagem)

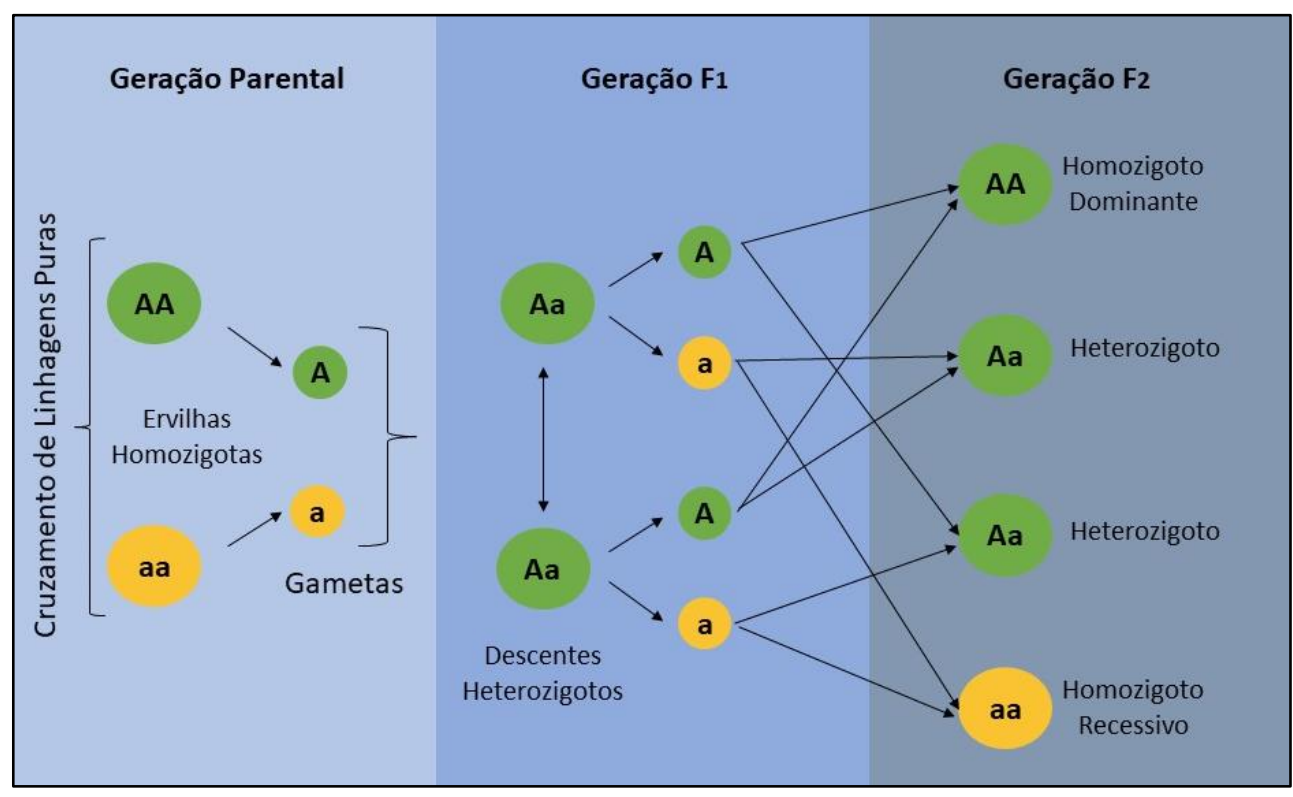

Fonte: Autoria própria (2019)

Por “Geração Parental”, Mendel denominou a primeira geração utilizada para o cruzamento, simbolizada no esquema por uma ervilha com vagem de coloração verde homozigoto dominante (AA) e outra amarela, homozigoto recessivo (aa). Como resultado, obteve a "Geração F1", totalidade de descentes verdes heterozigotos (Aa). Em seguida, ISSN 2526-2882 
autofecundou-se esses descendentes, obtendo três verdes (um homozigoto dominante e dois heterozigotos) e um amarelo (homozigoto recessivo), "Geração F2" (SNUSTAD e SIMMONS, 2001).

A partir de observações, Mendel identificou a cor verde presente em todas as gerações e ausência de amarela na Geração F1 e reaparecimento na F2. Por esse motivo, concluiu que as ervilhas com vagens verdes tinham caráter dominante, que se sobressaíam sobre as amarelas, recessivas (AMABIS; MARTHO, 1990). Testadas diferentes características, confirmou-se a predominância de algumas diante de outras, evidências que formularam "[...] o princípio da dominância ou, primeira lei de Mendel que diz que em um heterozigoto, um alelo pode encobrir a presença de outro e, o princípio da segregação que diz que em um heterozigoto, dois alelos diferentes se segregam um do outro durante a formação de gametas". (ASTRAUSKAS et al., 2009, p. 4).

Por fim, apresentou-se algumas características humanas que seguem os princípios da Primeira Lei de Mendel, são exemplos: destro (dominante) ou canhoto (recessivo), lóbulo da orelha preso (recessivo) ou solto (dominante), inserção dos cabelos na cabeça em linha frontal reta (recessivo) ou em bico (dominante) e capacidade enrolar a língua em " $U$ ” (dominante) (BAIOTTO, 2017). Em duplas, analisaram essas características nos colegas e registraram no caderno os possíveis genótipos, sendo a conferência realizada oralmente. Dispondo de espelhos ou solicitando previamente, a atividade pode ser realizada individualmente.

No segundo encontro, com duração de 1 hora, foi proposto a leitura e interpretação individual de uma charge, uma tirinha e dois exercícios de múltipla escolha, registrados no portfólio para posterior feedback. Escolheu-se os dois primeiros instrumentos pois, geralmente, encantam os estudantes pela criatividade, crítica, humor, sarcasmo e questionamentos que apresentam em seu conteúdo (MEHES; MAISTRO, 2012). Além disso, são gêneros riquíssimos em intertextualidade (articulação entre a linguagem verbal e não verbal), desenvolvendo o raciocínio e a análise do que está subentendido (ALVES; PEREIRA; CABRAL, 2013).

A tirinha era composta por dois quadros e quatro personagens, especificados com os seguintes genótipos: mãe (Aa), Júnior (aa), Alex (AA) e carteiro (Aa). No primeiro quadro, apresentava o personagem Alex se referindo ao Júnior como seu filho e, no segundo, mostrava o carteiro. Foi escolhida por explicitar, através do genótipo, que Alex não é o pai biológico do menino. E que a combinação dos genes da mãe e do carteiro são compatíveis com os do garoto.

Na charge, Bart Simpson, pautado em conceitos de genética, ironizava Skinner por têlo acusado de arremessar ervilhas nos colegas, devendo os estudantes justificarem se ele falava a verdade ou mentia. O diálogo entre os personagens é apresentado a seguir:

Skinner: "BART SIMPSON! Me informaram que você arremessou em seus colegas as sementes das ervilhas que estavam no laboratório". 
Bart: "Isso não é verdade, diretor Skinner! As sementes do laboratório são amarelas e as que atiraram nos alunos são homozigotas recessivas".

Já os exercícios de múltipla escolha (Imagem 2), intencionavam a familiarização com esse formato, pois muitos desejam prestar concursos e vestibulares. À propósito, apenas 50\% da turma já havia utilizado esse instrumento na EJA.

Imagem 2: Questões de múltipla escolha utilizadas como instrumento de avaliação

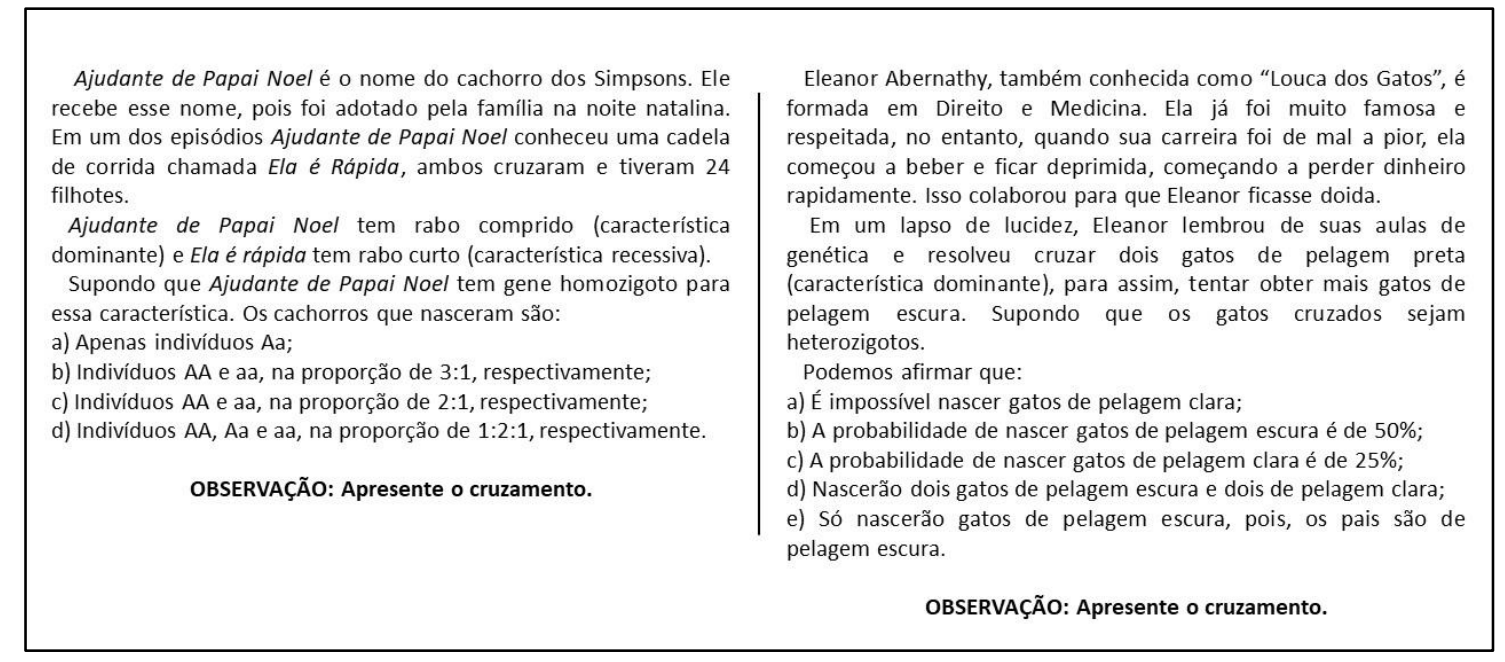

Fonte: Autoria própria (2019).

Destaca-se que o contexto da EJA é demarcado pela diversidade: trabalhadores, aposentados, jovens retidos ou em busca do primeiro emprego, enfim, uma infinidade de sujeitos com contextos, histórias e personalidades concretas e distintas (ARROYO, 2005; BRUNEL, 2014; FREIRE; NOGUEIRA, 1993; SOUZA, 2011). Sendo os diferentes níveis de aprendizagem um dos desafios durante o estágio, elencou-se como estratégia disponibilizar atividades extras, na qual, deveriam atribuir os possíveis fenótipos e genótipos para a característica destro e canhoto das famílias Simpson e Bouvier.

No terceiro encontro, 1 h3omin, realizou-se o feedback das atividades. Iniciou-se pela revisão do conteúdo abordado, com foco nos conceitos de alelos, gene dominante, gene recessivo, homozigose, heterozigose, genótipo e fenótipo. Projetou-se uma questão semelhante a aplicada e desenvolveu-se o cruzamento proposto por Mendel. As atividades previamente corrigidas foram devolvidas para que refizessem, caso julgassem necessário. Por fim, registraram nos portfólios se já haviam trabalhado com charges, tirinhas e questões de múltipla escolha anteriormente na EJA e também as classificaram quanto ao grau de complexidade: fácil, razoável ou difícil.

Para apresentação dos dados empíricos, as respostas foram categorizadas em ideais, adequadas e inadequadas, especificados os critérios na seção seguinte. A análise por idade considerou três faixas diferentes: (A) 20 anos ou menos, (B) entre 21 e 30 (C) e 31 ou mais, oito estudantes em cada. 


\section{Percepções a partir dos instrumentos utilizados}

A partir da tirinha, foi analisado o domínio conceitual sobre a percepção da combinação dos genes e relação entre os personagens, no qual 96\% afirmaram que o carteiro é pai biológico do Jr. E uma estudante, preferiu defini-los como "[...] parentes, pois um tem 'aa' e outro 'Aa', os genes do Júnior fecha com a mãe e o carteiro, então ele poderia ser o pai, mas não dá para afirmar" (E21). As respostas desses estudantes estão corretas porque os genótipos atribuídos esclarecem que Alex não é o pai biológico do menino, mas subentende a relação dos personagens entre si.

Considera-se genótipo, o conjunto de genes (ou um par de alelos em particular), representados através da simbologia, que expressam uma característica (SNUSTAD; SIMMONS, 2001). Alex, homozigoto dominante (AA) para determinada característica, não pode gerar descendentes recessivos (aa), Júnior.

Ainda nesta atividade, três estudantes mencionaram Alex como padrasto do garoto: “A mãe do Jr. teve o filho com o carteiro, mas Alex o criou” (E5); “O carteiro é o pai de Júnior, um casal separado" (E9); "O Júnior é o filho do carteiro de outro casamento de sua mãe e agora é o Alex que o cria.” (E14). A conformação de família é semelhante à vivenciada por eles, pois dois têm os pais separados e outro mora com a madrasta.

De acordo com Kosik (1985), a realidade apresenta-se como uma atividade prático sensível, na qual, as pessoas expressam-na de maneiras distintas, de acordo com suas necessidades e contextos vivenciados. Possivelmente, esses estudantes identificaram uma família na tirinha e não um elemento satírico, possível traição da mãe com o carteiro.

As justificativas para comprovação das respostas, demonstraram que 37,5\% descreveram e mostraram através de cruzamentos, que a combinação do genótipo da mãe e do carteiro é compatível com o Jr., desempenho ideal, conforme Quadro o1.

Quadro 1: Análise da tirinha proposta como instrumento de avaliação

\begin{tabular}{|l|c|c|c|c|c|}
\hline \multicolumn{1}{|c|}{ Justificativa } & \multirow{2}{*}{ Parecer } & \multicolumn{2}{|c|}{ Análise por idade } & Análise \\
\cline { 5 - 6 } & & $\leq \mathbf{2 0}$ & $\mathbf{2 1 - 3 0}$ & $\geq \mathbf{3 1}$ & geral \\
\hline $\begin{array}{l}\text { Descreveram que a combinação do genótipo da } \\
\text { mãe e do carteiro é compatível com o do Jr. E } \\
\text { comprovaram através do cruzamento. }\end{array}$ & Ideal & $50 \%$ & $37,5 \%$ & $25 \%$ & $37,5 \%$ \\
\hline $\begin{array}{l}\text { Descreveram que a combinação do genótipo da } \\
\text { mãe e do carteiro é compatível com o do Jr. }\end{array}$ & Adequado & $25 \%$ & $12,5 \%$ & $37,5 \%$ & $25 \%$ \\
\hline $\begin{array}{l}\text { Comprovaram através do cruzamento que o Alex } \\
\text { não é o pai Biológico do Jr. }\end{array}$ & Adequado & $25 \%$ & $25 \%$ & $25 \%$ & $25 \%$ \\
\hline Não justificaram & Inadequado & - & $25 \%$ & $12,5 \%$ & $12,5 \%$ \\
\hline
\end{tabular}

Fonte: Autores (2019).

A análise por idade inferiu que os estudantes com menos de 20, tiveram melhor desempenho, $50 \%$ ideal e 50\% adequado. O grupo relatou familiaridade com esse instrumento, 
visualizado em redes sociais, jornais e livros didáticos, conforme excertos: "Nunca trabalhei com tirinhas na EJA, mas gosto das do Garfield e da Mafalda" (E14), "[...] vejo mais no Facebook e nos jornais, são bem engraçadas" (E4), "Já trabalhei em Português antes de entrar na EJA, mas é a primeira vez em Ciências" (E2). Supõe-se que a facilidade dos jovens também esteja relacionada a pouca ou ininterrupção dos estudos, pois três nunca pararam, apenas trocaram o ensino sequencial pela EJA e os outros cinco tiveram uma descontinuidade inferior a um ano. Na charge, alguns estudantes apresentaram dificuldade para entender o diálogo de Skinner e Simpson. Por esse motivo, para auxiliar na interpretação, solicitou-se que escrevessem os possíveis fenótipos e genótipos das cores das sementes. Poderiam colocar uma característica abaixo da outra ou construir quadros para organização das informações. Por exemplo:

Fenótipo: cor amarela > Genótipo: homozigoto dominante (AA) ou heterozigoto (Aa).

Fenótipo: cor verde > Genótipo: homozigoto recessivo (aa).

O Quadro 02 mostra que 79\% formularam corretamente o solicitado, exemplificado no depoimento de E6: “[...] escrever ajudou a visualizar melhor e interpretar", relato semelhante de E25: "achei difícil, mas depois que fiz o quadro, consegui”.

Quadro 2: Atribuição do fenótipo e genótipo das cores das sementes das ervilhas

\begin{tabular}{|c|c|c|c|c|c|}
\hline \multirow{2}{*}{ Justificativa } & \multirow{2}{*}{ Parecer } & \multicolumn{3}{|c|}{ Análise por idade } & \multirow{2}{*}{$\begin{array}{l}\text { Análise } \\
\text { geral }\end{array}$} \\
\hline & & $\leq \mathbf{2 0}$ & 21-30 & $\geq \mathbf{3 1}$ & \\
\hline $\begin{array}{l}\text { No fenótipo amarelo escreveram o genótipo } \\
\text { homozigoto dominante (AA) e heterozigoto } \\
\text { (Aa) e no fenótopo verde representaram } \\
\text { homozigoto recessivo (aa) }\end{array}$ & Ideal & $87,5 \%$ & $87,5 \%$ & $62,5 \%$ & $79 \%$ \\
\hline $\begin{array}{l}\text { Escreveram que as ervilhas amarelas são } \\
\text { dominantes e as verdes recessivas, mas não } \\
\text { representaram os genótipos, conforme } \\
\text { solicitado. }\end{array}$ & Adequado & $12,5 \%$ & - & $25 \%$ & $12,5 \%$ \\
\hline $\begin{array}{llll}\text { Inverteram os } & \text { genótipos } & \text { ou } & \text { não } \\
\text { responderam }\end{array}$ & Inadequado & - & $12,5 \%$ & $12,5 \%$ & $8,5 \%$ \\
\hline
\end{tabular}

Fonte: Autores (2019).

A análise por idade mostra que os estudantes com mais de 31 anos tiveram mais dificuldade nesta atividade. Os mais velhos relataram que o tempo fora dos bancos escolares prejudica seu desenvolvimento, conforme excertos: "[...] parei de estudar a 40 anos, voltei para EJA para me aposentar ganhando um pouquinho mais, [...] então estou enferrujada com o conteúdo" (E16), “[...] parei por 37 anos, [...] até que interpretar não é difícil, pois leio bastante, mas o conteúdo demoro mais para entender"(E25). Estes trechos são de estudantes de 57 e 70 anos, respectivamente.

No questionamento seguinte: “Bart Simpson está falando a verdade?”, 87,5\% justificaram que sim, citando que as sementes do laboratório eram amarelas (dominantes) e as arremessadas eram verdes, homozigotas recessivas - resposta correta, conforme Quadro 3. 
Quadro 3: Análise da charge proposta como instrumento de avaliação

\begin{tabular}{|l|c|c|c|c|c|}
\hline \multicolumn{2}{|c|}{ Justificativa } & \multirow{2}{*}{ Parecer } & \multicolumn{2}{|c|}{ Análise por idade } & Análise \\
\cline { 3 - 6 } & $\mathbf{2 0}$ & $\mathbf{2 1 - 3 0}$ & $\geq \mathbf{3 1}$ & geral \\
\hline $\begin{array}{l}\text { Afirmaram que Bart falava a verdade, } \\
\text { citando que as sementes do laboratório eram } \\
\text { amarelas (dominantes) e as arremessadas } \\
\text { eram verdes, homozigotas recessivas. }\end{array}$ & Ideal & $100 \%$ & $87,5 \%$ & $75 \%$ & $87,5 \%$ \\
\hline $\begin{array}{l}\text { Afirmaram que Bart falava a verdade, mas } \\
\text { não justificaram. }\end{array}$ & Inadequado & - & $12,5 \%$ & $12,5 \%$ & $8,5 \%$ \\
\hline $\begin{array}{l}\text { Afirmaram que Bart mentia, mas não } \\
\text { justificaram. }\end{array}$ & Inadequado & - & - & $12,5 \%$ & $4 \%$ \\
\hline
\end{tabular}

Fonte: Autores (2019).

Indagados sobre terem deixado a justificativa em branco, dois $(8,5 \%)$ afirmaram que não souberam interpretar e um se equivocou ao explicar o porquê Bart mentia, inverteu o genótipo. Esse questionamento se faz necessário, pois assim como nas tirinhas, as propostas desse gênero textual, podem proporcionar diversas possibilidades de compreensão de textos e imagens, que perpassam diferentes óticas dependendo da perspectiva e argumentação de cada um (SOUSA; SOUZA, 2016). Ou seja, do mesmo modo que alguns perceberam satiridade na tirinha e outros visualizaram uma conformação de família, na charge poderiam questionar como o primogênito Simpson conhecia as ervilhas do laboratório e as arremessadas, cientes de sua personalidade indisciplinada e problemática.

Destaca-se que esses instrumentos podem ser utilizados com diferentes intencionalidades: diagnosticar, contextualizar, problematizar e avaliar (MEHES; MAISTRO, 2012). A apropriação enquanto instrumento avaliativo na EJA constituiu-se como uma tentativa de ruptura do ensino bancário descrito por Freire (2015), pois a interpretação e a argumentação não são estanques porque não se pautam em respostas prontas. A tirinha e a charge continham evidências científicas que necessitavam de aporte teórico-conceitual, bem como capacidade de leitura e interpretação.

Para verificar a aplicação do conhecimento prático, foram desenvolvidos dois exercícios de múltipla escolha referentes ao conteúdo da Primeira Lei de Mendel, resultados apresentados no Quadro 4.

Quadro 4: Análise das questões de múltipla escolha como instrumento de avaliação

\begin{tabular}{|l|c|c|c|}
\hline \multicolumn{1}{|c|}{ Justificativa } & Parecer & $\begin{array}{c}\text { Pré- } \\
\text { feedback }\end{array}$ & $\begin{array}{c}\text { Pós- } \\
\text { feedback }\end{array}$ \\
\hline $\begin{array}{l}\text { Extraíram as informações de ambas as questões, } \\
\text { realizaram o cruzamento marcaram a alterativa correta. }\end{array}$ & Ideal & $37,5 \%$ & $71 \%$ \\
\hline $\begin{array}{l}\text { Marcaram a alternativa incorreta ou deixaram-na em } \\
\text { branco em pelo menos uma questão. Mas extraíram as } \\
\text { informações de ambas e realizaram o cruzamento } \\
\text { corretamente. }\end{array}$ & Adequado & $46 \%$ & $25 \%$ \\
\hline $\begin{array}{l}\text { Marcaram a alternativa incorreta ou deixaram-na em } \\
\text { branco. Não extraíram as informaçôes ou erraram o } \\
\text { cruzamento. }\end{array}$ & Inadequado & $16,5 \%$ & $4 \%$ \\
\hline
\end{tabular}

Fonte: Autores (2019). 
Percebeu-se que somente $37,5 \%$ acertaram as questões em sua totalidade, $46 \%$ apesar de extraírem os dados corretamente e cruzarem as informações, erraram ou não assinalaram a alternativa correta. A falta de familiaridade pode ter contribuído, pois metade nunca experienciou esse instrumento. Após of feedback o quantitativo aumentou para 71\%.

Sinaliza-se a relevância de utilizá-lo com mais frequência na EJA, uma vez que, muitos manifestaram interesse de seguir seus estudos e fazer concursos públicos. O Exame Nacional do Ensino Médio (ENEM), a Prova Teórica de Primeira Habilitação e os concursos são exemplos de situações em que irão se deparar com esse formato de questão.

Por fim, a percepção sobre o desempenho dos estudantes permitiu aos pesquisadores organizarem um feedback direcionado às dificuldades. Por exemplo: como ainda não havia evidências de que todos entenderam os conceitos de genótipo e fenótipo, estruturou-se uma apresentação com slides desses conceitos. Além disso, foram refeitas questões de múltipla escolha semelhantes às aplicadas, mostrando como extrair os dados, realizar o cruzamento e marcar a alternativa.

$\mathrm{Na}$ devolutiva, seis complementaram as respostas da tirinha, seis algum aspecto relacionado a charge e quinze às questões de múltipla escolha. Observou-se adequações, inclusive, em respostas corretas. Conforme corrobora Vasconcelos, Praia e Almeida (2003), o feedback constitui-se para o professor como uma base de instrução e suporte de verificação dos resultados de aprendizagem e para estudantes serve como retorno da acuidade de suas respostas.

Essa ferramenta deve ser utilizada, principalmente na EJA, pois retroalimenta o conhecimento. Quando um conceito científico é apresentado pela primeira há troca de saberes entre estudante-professor e, consequentemente, (re)construção do conhecimento prévio. Ao realizar o feedback, o educador já possui as primeiras impressões das dificuldades apresentadas pela turma e os conceitos já são naturais para os educandos. (STOLL, 2017). Sua ausência pode levar o estudante a interpretar seu desempenho de maneira inadequada ou equivocada, gerando falsa confiança ou medo do erro (ZEFERINO; DOMINGUES; AMARAL, 2007).

\section{Algumas considerações sobre o percurso}

A complexibilidade do conteúdo de genética, considerado pelos estudantes como um dos mais difíceis do Ensino de Biologia (BORGES; SILVA; REIS, 2017; MOURA et al, 2013), requer a escolha de atividades diversificadas. A experiência de estágio vivenciada na EJA considerou as individualidades de cada um dos sujeitos, e as atividades foram elaboradas respeitando as diferentes formas e tempos de aprender. 
De acordo com Brunel (2014) e Souza (2011) a pluralidade dos educandos requer novas formas de ensinar, de aprender e de se reinventar, e a utilização de diferentes estratégias (charges, tirinhas, questões de múltipla escolha e demais instrumentos avaliativos), propiciou a maioria dos estudantes diferenciar conceitos de genética, tais como, fenótipo e genótipo, homozigoto e heterozigoto, ampliando a capacidade de análise, interpretação, argumentação e raciocínio porque ultrapassam a mecanicidade e arbitrariedade do ensino tradicional.

Por fim, salienta-se que além da diversidade de instrumentos torna-se importante a correção e devolutiva por parte do professor. O feedback possibilita ao professor reavaliar a sua prática e redirecionar o planejamento e ao estudante revisitar cada uma das atividades, analisando suas aprendizagens, reorganizando seu processo de estudo a partir de suas fragilidades e tendo autonomia para corrigi-las se achar necessário.

A participação ativa do estudante também no registro de suas percepções quanto as estratégias utilizadas, atividades que mais gostaram, momentos de dificuldade, causas da dificuldade, como a explicitada na questão de múltipla escolha, formato de questão pouco usado pelos professores, revela que necessidades como prestar concursos e vestibulares, devem ser consideradas.

\section{Referências}

ARROYO, M. Educação de Jovens e Adultos: um campo de direitos e responsabilidade pública. In: SOARES, L. J. G. Diálogos na educação de jovens e adultos. Belo Horizonte: Autêntica, 2005.

ALVES, T. L. B.; PEREIRA, S. S.; CABRAL, L. do N. A utilização de charges e tiras humorísticas como recurso didático-pedagógico mobilizador no processo de ensino-aprendizagem da Geografia. Educação, Santa Maria, v. 38, n. 2, p. 417-432, maio/ago, 2013.

AMABIS, J.P.; MARTHO, G.R. Fundamentos da Biologia Moderna. 1. ed. São Paulo: Moderna, 1990. p. 325-332.

ASTRAUSKAS, J. P. et al. As Leis da Herança por Gregor Johann Mendel, uma e revolução genética. Revista Científica Eletrônica de Medicina Veterinária, Ano VII, n. 13, p. 1-6, 2009.

BAIOTTO, C. R. Caracteres humanos utilizados no ensino dos padrões de herança mendelianos. 2017. 209f. Tese (Mestrado em Educação em Ciências: Química da Vida e Saúde), Programa de Pós-Graduação em Educação em Ciências: Química da Vida e Saúde, Universidade Federal de Santa Maria, UFSM, Santa Maria, 2009.

BORGES, C. K. G. D.; SILVA, C. C. da; REIS, A. R. H. As dificuldades e os desafios sobre a aprendizagem das Leis de Mendel enfrentados por alunos do Ensino Médio. Revista Experiências em Ensino de Ciências, v. 12, n. 6, p. 61-75, 2017. 
BRUNEL, C. Jovens cada vez mais jovens na Educação de Jovens e Adultos. 3 ed. Porto Alegre: Mediação, 2014.

FREIRE, P.; NOGUEIRA, A. Que fazer: teoria e prática em educação popular. 4. ed. Rio de Janeiro: Vozes, 1993.

FREIRE, P. Pedagogia do oprimido. 51. ed. Rio de Janeiro: Paz e Terra, 2015.

GRIFFITHS, A.J.F et al. Introdução a Genética. 6. ed. Rio de Janeiro: Guanabara Koogan, 1998. p. 21-29.

LINHARES, S.; GEWANDSZNADJER, F. Biologia hoje. 1. ed. v. 3. São Paulo: Ática, 2010.

LOPES, A. C. Os Parâmetros Curriculares Nacionais para o Ensino Médio e a submissão ao mundo produtivo: o caso do conceito de contextualização. Educação \& Sociedade, Campinas, v. 23, n. 80, p. 386-400, 2002.

MEHES, R.; MAISTRO, V. I. de A. A aprendizagem de biologia mediada por quadrinhos e/ ou charges. Revista eletrônica pró-docência, v 1, n 1, jan/jun. 2012.

MOURA, J. et al. Biologia/Genética: o ensino de biologia, com enfoque a genética, das escolas públicas no Brasil - breve relato e reflexão. Semina:- Ciências Biológicas e da Saúde, Londrina, v. 34, n. 2, p. 167-174, jul./dez, 2013.

SNUSTAD, D.P.; SIMMONS, M.J. Fundamentos de Genética. 2. ed. Rio de Janeiro: Guanabara Koogan, 2001. p. 47-52.

SOUSA, A. M. de; SOUZA, G. N. de. Charge: análise e aplicabilidade do gênero no processo de Leitura e produção textual. Revista Tropos, v. 5, n. 1, p. 1-10, 2016.

SOUZA, M. A. Educação de Jovens e Adultos. 2. ed. rev. Curitiba: Ibpex, 2011.

STOLL, V. G. O portfólio como instrumento didático-metodológico no processo avaliativo de Ciências na Educação de Jovens e Adultos. 2017. 93f. Monografia (Licenciatura em Ciências da Natureza), Universidade Federal do Pampa, UNIPAMPA, Dom Pedrito, 2017.

VASCONCELlOS, C. dos S.; PRAIA, J. F.; ALMEIDA, L. S. Teorias de aprendizagem e o ensino/aprendizagem das ciências: da instrução à aprendizagem. Revista Psicologia Escolar e Educacional, v. 7, n. 1, p. 11-19, 2003.

ZEFERINO, A. M. B.; DOMINGUES, R. C. L.; AMARAL, E. Feedback como estratégia de aprendizado no ensino médio. Revista Brasileira de Educação Médica, v. 31, n. 2, p. 176-179, 2007.

\section{Biografia Resumida}

Vitor Garcia Stoll: Professor municipal de Dom Pedrito/RS. Licenciado em Ciências da Natureza e Mestrando em Ensino pela Universidade Federal do Pampa.

ISSN 2526-2882 
Lattes: http://lattes.cnpq.br/8592218192423206

Contato: vitorgarciastoll@gmail.com

Crisna Daniela Krause Bierhalz: Professora adjunta da Universidade Federal do Pampa - Campus Dom Pedrito. Doutora em Educação pela Pontífica Universidade Católica do Rio Grande do Sul.

Lattes: http://lattes.cnpq.br/8524665688345631

Contato: crisnakrause@gmail.com 